\title{
A combination of statistical methods for the analysis of the relative validation data of the quantitative food frequency questionnaire used in the THUSA study
}

\author{
UE MacIntyre ${ }^{1, *}$, CS Venter ${ }^{2}, \mathrm{HH}$ Vorster ${ }^{2}$ and HS Steyn ${ }^{3}$ \\ 'Department of Paediatrics and Child Health, PO Box 168, Medical University of Southern Africa, \\ 0204 South Africa: ${ }^{2}$ Department of Nutrition and Family Ecology, Potchefstroom University for Christian \\ Higher Education, South Africa: ${ }^{3}$ Statistical Services, Potchefstroom University for Christian Higher Education, \\ South Africa
}

Submitted 10 September 1999: Accepted 14 February 2000

\begin{abstract}
Objective: To apply structural equation modelling (SEM) and estimation of variance components to the relative validation data obtained from the quantitative food frequency questionnaire (QFFQ) used in the Transition, Health and Urbanisation in South Africa (THUSA) study.

Design: A cross-sectional study.

Setting: A community-based field study in an African population conducted during 1996.

Subjects: Residents of the North West Province, South Africa, aged between 15 and 65 years.

Methods: Relative validity of the QFFQ was tested against 7-day weighed food records, 24-hour urinary nitrogen (UN) excretion and estimated basal metabolic rate (BMR). SEM and estimation of variance components were applied to the logtransformed energy, protein, fat, calcium, iron, vitamin A and vitamin C intakes. UN excretion was used as a biomarker in the application of the SEM to protein and estimated BMR to energy intakes.

Results: Constant bias $\left(\alpha_{\mathrm{Q}}\right)$ derived by the SEM varied from 0.85 (vitamin C) to 5.8 (energy). There was significant proportional bias for all nutrients except vitamin C. Validation coefficients $(\rho(Q, T))$ varied from 0.3 (fat, calcium, iron) to 0.7 (vitamin C). The inclusion of estimated BMR in the SEM for energy increased $\rho(Q, T)$ from 0.38 to 0.42 . The estimation of variance components gave slightly lower correlations for the relationship between intakes from the QFFQ and the unknown true intake.

Conclusions: Robust statistical methods were successfully applied in a relative validation study for a QFFQ in an African population. Estimated BMR as a biomarker for energy intake produced more meaningful results than UN excretion as a biomarker for protein intake.
\end{abstract}

Keywords

Dietary surveys

Relative validity Statistical methods
Relative validation of a dietary intake assessment instrument involves the comparison of a less established or detailed method such as a food frequency questionnaire against a more detailed or established method, usually a weighed record ${ }^{1,2}$. To be useful, this comparison must be expressed in relevant statistical terms. In the past, various forms of correlation coefficients have been used to estimate the agreement between the test method and the established reference method. The most frequently used method has been the Pearson correlation coefficient ${ }^{1}$. Some researchers, however, have used the Spearman rank correlation coefficient ${ }^{2-4}$ while others such as Lee $^{5}$ have used intraclass correlation coefficients to describe the relationship between nutrient intakes derived from the test and reference methods.
Recently, several authors have questioned the appropriateness of the correlation coefficient as an estimate of agreement in relative validation ${ }^{6-8}$. There are a number of reasons for this viewpoint. First, the correlation coefficient measures the strength of the relationship between two variables, not the agreement between them ${ }^{9}$. Second, the strength of the correlation depends on the range of the true value in the sample? . Third, correlation coefficients are strongly influenced by the characteristics and size of the study sample 6 .

The reference measure is assumed to represent the true intake of the sample. In reality, however, the reference method itself is subject to both random and systematic and inter- and intraindividual errors ${ }^{10,11}$. Figure 1 shows the possible relationships between the 


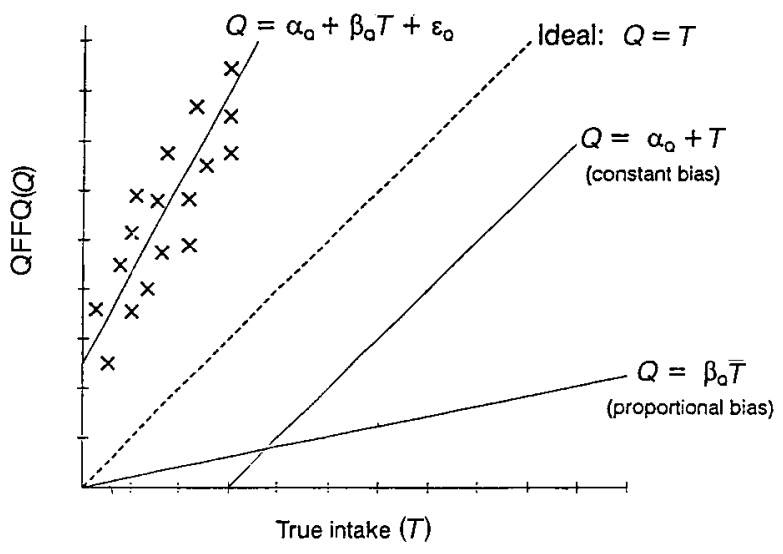

Fig. 1 Graph showing the ideal, constant bias, proportional bias and real relationship between the quantitative food frequency questionnaire (QFFQ) intake and true intake

intake obtained from the test method, a QFFQ and the true intake.

This doubt of the ability of correlation coefficients to measure agreement and the fact that there is no true 'gold standard' against which an instrument can be validated have led researchers to investigate alternative methods of analysing validation study data ${ }^{8,10,12}$. Among these methods have been the techniques proposed by Bland and $\operatorname{Altman}^{13}$, the estimation of between and within person variance ${ }^{12}$ and combinations of reference methods and biomarkers, known as the 'method of triads' described for the European Prospective Investigation into Cancer and Nutrition (EPIC) Project ${ }^{14}$.

In 1994, Kaaks and co-workers ${ }^{11}$ described the use of SEM using different numbers of variables and including a biomarker in the model to determine the agreement of nutrient intakes obtained from a food frequency questionnaire with those obtained from 7-day weighed records. Beaton ${ }^{10}$, recognizing that the reference method itself is subject to errors, developed an approach to examine the error terms in the estimation of dietary intake when recalls or records over a number of days are used as the reference method.

The purpose of the present paper was to apply and adapt the methods described by Kaaks et al. ${ }^{11}$ and Beaton ${ }^{10}$ to the results obtained in the relative validation study of the QFFQ developed to assess the dietary intakes of the African population of the North West Province, South Africa as part of the THUSA study.

\section{Methods}

\section{Relative validation study}

The relative validation study was carried out on a sample of 74 ( 55 females and 19 males) volunteers who had participated in the THUSA study during 1996. The test method was a culture-sensitive QFFQ consisting of 145 food items. Food portion sizes were estimated from a food portion photograph book of 37 common foods shown in three or four portion sizes. Seven-day weighed food records were used as the reference method. Each subject was given a scale with a capacity of $500 \mathrm{~g}$ with $5 \mathrm{~g}$ graduations (EKS, France), a measuring jug $(500 \mathrm{ml}$ capacity, $25 \mathrm{ml}$ graduations) and a set of four measuring spoons $(1,2,5,12.5 \mathrm{ml})$. The weighed records were checked during and at the end of the recording period.

Subjects were weighed in light clothing without shoes to the nearest $0.05 \mathrm{~kg}$ on a calibrated portable electronic bathroom scale (Precision Health Scale, A \& D Company, Japan). Height was measured with an upright stadiometer placed against a perpendicular wall to the nearest $0.5 \mathrm{~cm}$. Age was calculated from the date of birth, obtained from the subject's identity document. BMR was estimated from the Schofield equations ${ }^{15}$.

A subsample of 46 of the 74 volunteers who kept food diaries made a single 24-hour urine collection. Completeness of the collections was checked using three, $80 \mathrm{mg}$ tablets of para-aminobenzoic acid (PABA; PABAcheck, Laboratories for Applied Biology, London) according to the methods described by Bingham and Cummings ${ }^{16}$. The volume of the 24-hour collection was recorded and four portions stored at $-20^{\circ} \mathrm{C}$ before analysis. PABA content of the urine specimens was analysed by chromatography ${ }^{16}$. Nitrogen was determined by the Kjeldahl technique.

The development of the QFFQ and the subjects and methods used in the relative validation study have been described in detail elsewhere ${ }^{17}$.

\section{Statistical analyses}

Nutrient analyses of both the QFFQ and weighed food records were done with the FoodFinder Dietary Analysis Program (a dietary analysis system developed by the South African Medical Research Council based on locally available foods and nutrient values obtained from international tables ${ }^{18}$.

The equivalent protein intake to the nitrogen content of the urine sample was adjusted for skin and faecal losses using the formula:

$$
\text { Protein intake }\left(\mathrm{g} \mathrm{day}^{-1}\right)=6.25(\mathrm{UUN}+0.031 \mathrm{BW}) \text {, }
$$

where UUN is urine urea nitrogen $\left(\mathrm{gl}^{-1}\right)$ and BW is body weight $(\mathrm{kg})^{19}$.

The statistical procedures were applied to energy, protein, fat, calcium, iron, vitamin A and vitamin C intakes. It was assumed that the results obtained from the comparison of energy and these nutrients would represent the whole $\operatorname{diet}^{20}$.

Intake values from the QFFQ and weighed food records were first transformed to improve normality using the Box-Cox power transformation

$$
y=\left(x^{\lambda}-1\right) / \lambda,
$$

where $\lambda=-0.28^{21}$. Since $\lambda$ did not differ significantly from zero, the data was thus logarithmically transformed. 


\section{Application of structural equation models}

Following the SEM as suggested by Kaaks et al. ${ }^{11}$, the nutrient intake obtained from the QFFQ $(Q)$ was assumed to be related to the true intake $(T)$ of the subjects by the equation:

$$
Q=\alpha_{\mathrm{Q}}+\beta_{\mathrm{Q}} T+\epsilon_{\mathrm{Q}}
$$

To estimate the accuracy (that is, the validity and precision) of an intake derived from the QFFQ $(Q)$, the size of the unknown error parameters $\alpha_{\mathrm{Q}}$, (constant bias), $\beta_{\mathrm{Q}}$ (proportional bias) and $\sigma^{2} \epsilon_{\mathrm{Q}}$ (variance of random errors) were needed. Ideally, these estimates would be obtained by comparing the intakes derived from the QFFQ with the true intake values. In reality, the true intake value can never be known and must be considered as a value of a latent variable $T$. Instead, the logarithmically transformed values from the QFFQ must be compared with a reference measurement $R$ (logarithmically transformed values from the 7-day weighed food record) which is related to the same latent variable but may itself contain some error, expressed by the following equation:

$$
R=\alpha_{\mathrm{R}}+\beta_{\mathrm{R}} T+\epsilon_{\mathrm{R}}
$$

Equations 1 and 2 define structural relations that would be expected between the measurements of $Q$ and $R$.

The correlation between the intake derived from the QFFQ $(Q)$ and the true intake $(T)$ is expressed as:

$$
\rho(Q, T)=\left(1+\left(\sigma^{2} \epsilon_{\mathrm{Q}} /\left(\beta_{\mathrm{Q}}^{2} * \sigma_{\mathrm{T}}^{2}\right)\right)^{-0.5},\right.
$$

where $\sigma_{\mathrm{T}}^{2}$ is the variance of the true intake $(T)$ and $\rho(Q, T)$ is known as the validity coefficient ${ }^{22}$. The CALIS procedure of the SAS version $6^{23}$ statistical programme was used to calculate the maximum likelihood estimates of the parameters. In the first application of the model, the mean intake of the 7-day weighed food record was used as the reference measure for each variable (method 1 as described by Kaaks et al. ${ }^{11}$ ). Kaaks and co-workers ${ }^{11}$, in their second method, used the mean of 3 days' intake and the mean of 4 days' intake of the 7-day weighed food records to provide an additional parameter. In an attempt to improve the correlation between the QFFQ and weighed food record, in the second application of the SEM in the present study, each day was treated as a separate entity thus providing seven parameters for the weighed food record.

For protein, the above model was applied to the results of 46 subjects for whom QFFQ, weighed food records and UN values were available. As the BMR could be calculated for all subjects in the validity sample, the use of BMR as a biomarker was applied to all 74 subjects.

\section{Estimation of correlation between $Q F F Q$ and weighed records to include the error components}

Beaton ${ }^{10}$ has described a different approach to describing the relationship between intakes obtained from a test

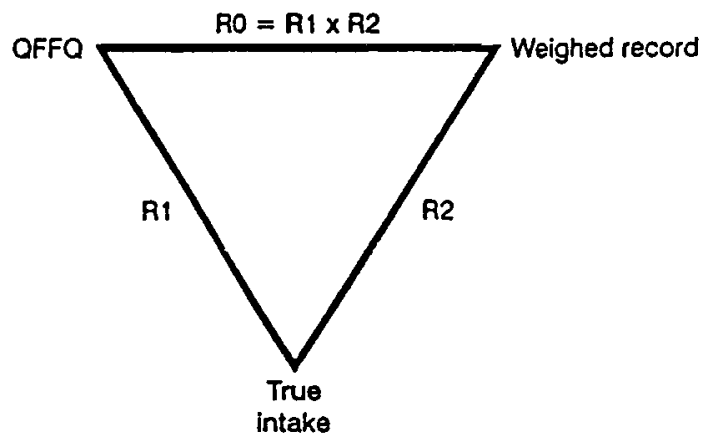

Fig. 2 Observed and estimated correlations between the quantitative food frequency questionnaire (QFFQ), weighed record and true (unknown) intake ${ }^{10}$. R0, correlation between QFFQ and weighed record; R1, correlation between QFFQ and true intake; R2, correlaton between weighed record and true intake

method and the true intake. This procedure estimates the within person and between person variance components by examining the correlations between the QFFQ, weighed food record and the true, but unknown, intake. Figure 2 depicts the relationships among the QFFQ (the test method), the weighed record (reference method) and the true intake. With reference to Fig. 2, the correlation between intakes from the QFFQ and the weighed food record, R0, can be directly estimated by the calculation of the Pearson correlation coefficient. In the present study, the correlation between the weighed food record and the true intake R2, was estimated by the method described by Dunn ${ }^{24}$ using the following formulae:

$$
\text { Correlation }(R, T)=\mathrm{R} 2=\left(r_{\mathrm{R}, 1}\right)^{-0.5}
$$

where $R$ is the intake from the weighed food record, $T$ is the unknown true intake and $r_{\mathrm{R}, 1}$ is the reliability of an individual weighed food record measurement (also known as the intrasubject correlation) given by:

$$
r_{\mathrm{R}, 1}=\left(S_{\mathrm{B}}^{2}-S_{\mathrm{W}}^{2}\right) /\left(S_{\mathrm{B}}^{2}+(k-1) S_{\mathrm{W}}^{2}\right),
$$

where $S_{\mathrm{B}}^{2}$ is the between subject mean square, $S_{\mathrm{W}}^{2}$ is the within subject mean square and $k$ is the number of repetitions of the weighed food record. The reliability of the mean of $k$ reference measurements, that is of seven weighed record measurements, was given by:

$$
r_{\mathrm{R}, \mathrm{k}}=k r_{\mathrm{R}, 1} /\left(1+(k-1) r_{\mathrm{R}, 1}\right)
$$

Returning to Fig. 2, R1, the correlation between intakes from the QFFQ and the true intake can be estimated from ${ }^{10}$ :

$$
\mathrm{R} 1=\mathrm{R} 0 / \mathrm{R} 2
$$

\section{Results}

Equation 1 gives the relation between the nutrient intake derived from the QFFQ $(Q)$ and the unknown true intake 
Table 1 Comparison of proportional bias $\left(\beta_{\mathrm{Q}}\right)$ and constant bias $\left(\alpha_{\mathrm{Q}}\right)$ calculated by the methods* adapted from Kaaks et al. ${ }^{11}$ applied to the validation data of a QFFQ used in an African population $(n=74)$

\begin{tabular}{|c|c|c|c|c|c|c|}
\hline \multirow[b]{2}{*}{ Variable } & \multicolumn{2}{|c|}{ Method 1} & \multicolumn{2}{|c|}{ Method 2} & \multicolumn{2}{|c|}{ Method 3} \\
\hline & $\beta_{Q}$ & $\alpha_{Q}$ & $\beta_{Q}$ & $\alpha_{Q}$ & $\beta_{\mathrm{Q}}$ & $\alpha_{Q}$ \\
\hline $\begin{array}{l}\text { Energy } \\
95 \% \mathrm{Cl}\end{array}$ & $\begin{array}{l}0.36 \\
0.12 \text { to } 0.60\end{array}$ & $\begin{array}{l}5.78 \\
3.61 \text { to } 7.96\end{array}$ & $\begin{array}{l}0.51 \\
0.10 \text { to } 0.76\end{array}$ & $\begin{array}{l}4.40 \\
1.04 \text { to } 7.77\end{array}$ & $\begin{array}{l}0.60 \\
-0.93 \text { to } 2.12\end{array}$ & $\begin{array}{l}3.62 \\
-10.28 \text { to } 7.51\end{array}$ \\
\hline $\begin{array}{l}\text { Protein } \\
95 \% \mathrm{Cl}\end{array}$ & $\begin{array}{l}0.33 \\
0.10 \text { to } 0.55\end{array}$ & $\begin{array}{l}2.78 \\
1.83 \text { to } 3.73\end{array}$ & $\begin{array}{l}0.56 \\
0.18 \text { to } 0.97\end{array}$ & $\begin{array}{l}1.75 \\
0.08 \text { to } 3.14\end{array}$ & & \\
\hline $\begin{array}{l}\text { Fat } \\
95 \% \mathrm{Cl}\end{array}$ & $\begin{array}{l}0.12 \\
0.028 \text { to } 0.20\end{array}$ & $\begin{array}{l}3.24 \\
2.54 \text { to } 3.94\end{array}$ & $\begin{array}{l}0.47 \\
0.03 \text { to } 0.90\end{array}$ & $\begin{array}{l}2.23 \\
0.42 \text { to } 4.03\end{array}$ & & \\
\hline $\begin{array}{l}\text { Calcium } \\
95 \% \mathrm{Cl}\end{array}$ & $\begin{array}{l}0.31 \\
0.06 \text { to } 0.56\end{array}$ & $\begin{array}{l}4.17 \\
2.64 \text { to } 5.70\end{array}$ & $\begin{array}{l}0.29 \\
0.03 \text { to } 0.55\end{array}$ & $\begin{array}{l}4.35 \\
2.77 \text { to } 5.94\end{array}$ & & \\
\hline $\begin{array}{l}\text { Iron } \\
95 \% \mathrm{Cl}\end{array}$ & $\begin{array}{l}0.22 \\
-0.25 \text { to } 0.47\end{array}$ & $\begin{array}{l}1.68 \\
1.10 \text { to } 2.26\end{array}$ & $\begin{array}{l}0.34 \\
0.01 \text { to } 0.67\end{array}$ & $\begin{array}{l}1.44 \\
0.72 \text { to } 2.16\end{array}$ & & \\
\hline $\begin{array}{l}\text { Vitamin A } \\
95 \% \mathrm{Cl}\end{array}$ & $\begin{array}{l}0.29 \\
0.17 \text { to } 0.46\end{array}$ & $\begin{array}{l}4.69 \\
3.58 \text { to } 5.81\end{array}$ & $\begin{array}{l}0.43 \\
0.16 \text { to } 0.69\end{array}$ & $\begin{array}{l}4.06 \\
2.52 \text { to } 5.61\end{array}$ & & \\
\hline $\begin{array}{l}\text { Vitamin C } \\
95 \% \mathrm{Cl}\end{array}$ & $\begin{array}{l}0.55 \\
0.34 \text { to } 0.77\end{array}$ & $\begin{array}{l}1.80 \\
0.95 \text { to } 2.66\end{array}$ & $\begin{array}{l}0.89 \\
0.37 \text { to } 1.40\end{array}$ & $\begin{array}{l}0.85 \\
-0.96 \text { to } 2.66\end{array}$ & & \\
\hline
\end{tabular}

* Method 1 adapted from method 1; method 2 adapted from method $2 \mathrm{~b}$; method 3 includes a biomarker and is adapted from method 3 (Kaaks et al. ${ }^{11}$ ).

(T). The coefficient $\alpha_{\mathrm{Q}}$ represents the constant bias and $\beta_{\mathrm{Q}}$ reflects the proportional bias. If the QFFQ was a perfect reflection of the true intake, there should have been no constant bias $(\alpha=0)$ and no proportional bias $(\beta=1)^{22}$. In addition, the validity coefficient $\rho(Q, T)$, that is, the correlation of the intake derived from the QFFQ and the true intake (Equation 3) should be high. Thus, the desired results are $\alpha_{\mathrm{Q}}$ approaching zero (95\% confidence interval (CI) including zero), $\beta_{\mathrm{Q}}$ close to one $(95 \% \mathrm{CI}$ including one) and a strong validity coefficient. Table 1 shows the $\beta_{\mathrm{Q}}$ and $\alpha_{\mathrm{Q}}$ calculated by various methods from the simplest based on mean of the intakes over the 7 days of the weighed food record (method 1), using each day of the 7-day weighed record as a separate parameter (method 2) and the inclusion of the biomarker (method 3 ). Table 2 shows the $\rho(Q, T)$ obtained from the above three methods. The Spearman rank correlation coefficients for the untransformed values of $Q$ in relation to $R$ are shown for comparison. The values for the relationships between the intakes obtained from the QFFQ and weighed food

Table 2 Comparison of $\rho(Q, T)$ calculated by the methods* adapted from Kaaks et al. ${ }^{17}$ applied to the validation data of a QFFQ used in an African population $(n=74)$

\begin{tabular}{lcccc}
\hline Variable & Method 1 & Method 2 & Method 3 & $\begin{array}{c}\text { Spearman rank } \\
\text { correlation } \\
\text { coefficient† }\end{array}$ \\
\hline Energy & 0.33 & 0.38 & 0.42 & 0.31 \\
Protein & 0.32 & 0.45 & & 0.30 \\
Fat & 0.29 & 0.31 & & 0.25 \\
Calcium & 0.28 & 0.31 & & 0.24 \\
Iron & 0.21 & 0.31 & & 0.20 \\
Vitamin A & 0.37 & 0.56 & & 0.22 \\
Vitamin C & 0.52 & 0.68 & & 0.59 \\
\hline
\end{tabular}

* Method 1 adapted from method 1; method 2 adapted from method $2 b$; method 3 includes a biomarker and is adapted from method 3 (Kaaks et al. ${ }^{11}$ ). † Spearman rank correlation coefficient of untransformed data. records, weighed food record and unknown true intake and QFFQ and unknown true intake according to the adapted method of Beaton ${ }^{10}$ are given in Table 3.

With regard to proportional bias, method 2 appeared to give values closer to one than method 1 for all nutrients except calcium. The only nutrient showing no significant proportional bias with method 2 was vitamin $C$. The energy calculations show the effect of including the error terms and the benefit of a biomarker. $\beta_{\mathrm{Q}}$ calculated with method 1 was the lowest, then increased to 0.5 on the second method, but the proportional bias was still significant. When the biomarker, BMR, was included as the third independent parameter, $\beta_{\mathrm{Q}}$ increased to 0.6 and, although the proportional bias was not significant, the 95\%CI was wide. The $\beta_{\mathrm{Q}}$ for protein showed a similar improvement between methods 1 and 2 . The attempt to include urinary protein as the third independent marker failed to produce a meaningful result. $\beta_{\mathrm{Q}}$ increased to 3 and although the $95 \% \mathrm{CI}$ included one, it was extremely wide (data not shown).

Table 3 Relationships between nutrient intakes from the QFFQ and weighed food record used in an African population and unknown true intake calculated from the adapted method of Beaton ${ }^{10}(n=74)$

\begin{tabular}{lccc}
\hline Variable & $R(Q \& R)^{\star}$ & $R(R \& T) \dagger$ & $R(Q \& T) \ddagger$ \\
\hline Energy & 0.33 & 0.91 & 0.36 \\
Protein & 0.31 & 0.89 & 0.35 \\
Fat & 0.28 & 0.85 & 0.33 \\
Calcium & 0.26 & 0.88 & 0.29 \\
Iron & 0.22 & 0.87 & 0.26 \\
Vitamin A & 0.35 & 0.79 & 0.44 \\
Vitamin C & 0.55 & 0.84 & 0.69
\end{tabular}

${ }^{*}$ Correlation between quantitative food frequency questionnaire and mean of weighed records.

† Correlation between mean of weighed records and true intake.

$\ddagger$ Correlation between quantitative food frequency questionnaire and true intake. 
When looking at the constant bias, $\alpha_{\mathrm{Q}}$, vitamin $\mathrm{C}$ was the only nutrient for which the 95\%CIs included zero with method 2. Direct comparison of the degree of constant bias between nutrients was not possible because of the differences in the scales of measurement and variation of the nutrient intakes. As for $\beta_{\mathrm{Q}}$, the value $\alpha_{\mathrm{Q}}$ for energy improved when BMR was used as the biomarker, but the model failed with the use of urinary protein.

Generally the highest validation coefficients were obtained with method 2 (Table 2). The reported intake of vitamin $\mathrm{C}$ appeared to be the closest to the true intake with no significant constant or proportional bias and a high validation coefficient. Except for fat, $R(Q, T)$ calculated using the method of Beaton ${ }^{10}$ (Table 3 ), fell between the results for $\rho(Q, T)$ obtained from method 1 and method 2. The inclusion of BMR as the biomarker improved the validation coefficient for energy. When urinary nitrogen was used as the biomarker for protein intake, the model failed due to a negative value for $\sigma^{2}$ $(-0.005)$.

Using the guidelines for strength of agreement quoted by Dunn $^{24}$, one nutrient (vitamin A) clearly had moderate agreement, energy and protein ranged from fair to moderate agreement, one nutrient (vitamin C) had moderate to substantial agreement and three nutrients (fat, calcium and iron) had fair agreement (Table 2). Overall agreement ranged from 0.2 (iron) to 0.7 (vitamin C) with a mean upper limit of agreement (obtained from method 2) of 0.41 ( $S D=0.14)$, in other words, moderate agreement.

The advantage of using the SEM is that it not only gives an objective measure of validity but also, by the calculation of $\alpha_{\mathrm{Q}}$ and $\beta_{\mathrm{Q}}$, provides a means of adjusting the reported nutrient intakes according to the constant and proportional bias, as well as identifying nutrients for which no adjustment is necessary. Adjustment of the reported intakes is by the following equation ${ }^{11}$ derived from Equation 1:

$$
Q^{\prime}=\left(Q-\alpha_{\mathrm{Q}}\right) / \beta_{\mathrm{Q}}
$$

To illustrate the application of the above equation, examples of mean reported intakes of 890 subjects interviewed using the QFFQ during the THUSA study and their adjusted values using the results of method 2 are shown in Table 4.

\section{Discussion}

In most published validation studies making use of biomarkers, the correlation coefficients of the biomarkers and the dietary intake measurement instrument have been reported separately ${ }^{25-29}$. It is not always clear how the results of the biomarkers relate to the correlation between the test and reference methods. The statistical method, using structural equation models, proposed by Kaaks et al. ${ }^{11}$ combines the findings obtained from the biomarker
Table 4 Mean reported intakes obtained from a QFFQ used in an African population, adjusted according to the equation $Q^{\prime}=\left(Q-\alpha_{Q}\right)$ / $\beta_{\mathrm{Q}}(n=890)$

\begin{tabular}{lcc}
\hline Variable & Mean reported intake & Mean adjusted intake \\
\hline Energy (kJ) & 8487 & 9058 \\
Protein (g) & 66.2 & 72.5 \\
Fat $(\mathrm{g})$ & 61.0 & 69.0 \\
Calcium (mg) & 489.0 & 1597.0 \\
Iron $(\mathrm{mg})$ & 9.0 & 15.1 \\
Vitamin A (RE) & 877.0 & 1391.7 \\
Vitamin C (mg) & 50.0 & 34.3 \\
\hline
\end{tabular}

with those from the correlation of the reference and test methods to give a single validity coefficient for a given nutrient. Also, the use of SEM, without the presence of a biomarker, takes account of the possibility that the random errors between measurement instruments and replicate measures are correlated, thus providing a more accurate measure of relative agreement than the Spearman rank correlation coefficient ${ }^{11}$. An additional advantage of the SEM technique is that it gives an estimate of the constant and proportional bias in the measurement of the intake of a given nutrient and provides a means of applying the findings of the validation study to the dietary intake results of the main study.

The method proposed by Beaton ${ }^{10}$ to estimate the components of variance of the QFFQ was also applied to determine whether results obtained would be similar to those of the SEM. In the light of the reservations expressed about the use of the correlation coefficient in validation studies $^{6-8,10}$, it was hoped that either or both of these methods would provide a feasible and useful alternative to the use of the Spearman rank correlation coefficient.

As expected, the first method of Kaaks et al. ${ }^{11}$ by which the mean intake obtained from the 7-day weighed record was compared to the QFFQ (method 1), yielded results very similar to those obtained by the application of the Spearman rank correlation. When each day of the 7-day weighed record was treated as a separate replicate (method 2), the values of the correlation improved for all variables tested.

An advantage of SEM is that it provides a measure of the constant and proportional bias present in the measurement instrument. Regarding proportional bias, SEM identified significant bias in energy and all nutrients tested with the exception of vitamin C. Importantly, the inclusion of BMR in the calculation removed the proportional bias from the estimate of energy. Several authors have questioned the validity of the use of the Schofield equations ${ }^{15}$ for the estimation of $\mathrm{BMR}^{30,31}$ on the basis that these equations have been found to overestimate BMR, in both tropical and temperate regions ${ }^{30,32-34}$. Thus, the use of the Schofield equations may not have given an accurate estimation of BMR in our population. Also, the use of BMR, instead of total energy expenditure (TEE) may have affected the results. TEE 
was not used as the estimation of activity levels in this population was difficult.

Constant bias was observed for all variables tested, except vitamin C. In practical terms, the presence of proportional bias is more important in dietary surveys than constant bias. Constant bias does not affect the ranking of individuals within the distribution, nor will it affect the comparison of intakes among subgroups of the sample. For example, if the QFFQ overestimated protein intake consistently by $10 \mathrm{~g}$, the intakes of all subjects would be $10 \mathrm{~g}$ higher than the true intake. Proportional bias, however, means that as the true intake increases the QFFQ proportionally underestimates or overestimates the true intake. This will affect both the ranking of individuals within the distribution as well as comparisons among subgroups. It cannot, therefore, be assumed that the QFFQ gives the same reflection of true intake for all nutrients or for all levels of intakes. The advantage of SEM, is that the estimates of constant and proportional bias provide a means of adjusting reported intakes to possibly give a closer estimate of true intakes.

The modified method of Beaton ${ }^{10}$ yielded higher correlations between the QFFQ and true intake than were obtained by the Spearman rank correlation, but lower values than the SEM. This may indicate that SEM, by making use of more parameters, is able to give a more precise estimate of validity. The method of Beaton ${ }^{10}$ also shows the relationship between the reference method and the true intake, which in the present study was close to perfect for all nutrients tested (0.79-0.91). It may be simpler to apply, requiring only the within and between person variances, calculated by the analysis of variance. In contrast, SEM requires fairly sophisticated software and statistical knowledge to implement. In a recent report, Ocké and Kaaks ${ }^{14}$ proposed a simplified method, known as the 'method of triads' to estimate the validity of a test measure. This method requires a biomarker, but is based on correlations between methods and does not require complicated calculations. An extension of the comparison of statistical methods in the present study would be to apply the method of Ocké and Kaaks ${ }^{14}$ and to compare the results to those obtained by the methods of Kaaks et al. ${ }^{11}$ and Beaton ${ }^{10}$.

As the development of sophisticated techniques for the validation of dietary intake assessment instruments has increased, so has the need for robust statistical methods with which to analyse the data. Our experience has shown that it was possible to apply sophisticated statistical methods to validation data collected in the setting of a developing country. Two important issues regarding the validation of dietary assessment instruments in developing countries need to be addressed. One is the identification and development of practical and reliable biomarkers. The other is the standardization of statistical techniques across all research centres to ensure quality and comparable relative validation results.

\section{References}

1 Willett W. Nutritional Epidemiology. Monographs in Epidemiology and Biostatistics, No. 15. Oxford: Oxford University Press, 1990.

2 Buzzard IM, Sievert YA. Research priorities and recommendations for dietary assessment methodology. Am. J. Clin. Nutr. 1994; 59 (Suppl.): S275-80.

3 Thompson RL, Margetts BM. Comparison of a food frequency questionnaire with a 10-day weighed record in cigarette smokers. Int. J. Epidemiol. 1993; 22: 824-33.

4 Bingham SA, Gill C, Welch A, et al. Comparison of dietary assessment methods in nutritional epidemiology: weighed records $v$ 24-h recalls, food-frequency questionnaires and estimated-diet records. Br. J. Nutr. 1994; 72: 619-43.

5 Lee J. Alternate approaches for quantifying aggregate and individual agreements between two methods for assessing dietary intakes. Am. J. Clin. Nutr. 1980; 33: 956-8.

6 Hebert JR, Miller DR. The inappropriateness of conventional use of the correlation coefficient in assessing validity and reliability of dietary assessment methods. Eur. J. Epidemiol. 1991; 7: 339-43

7 Bellach B. Remarks on the use of Pearson's correlation coefficient and other association measures in assessing validity and reliability of dietary assessment methods. Eur.J. Clin. Nutr. 1993; 47 (Suppl. 2): S42-5.

8 Delcourt C, Cubeau J, Balkau B, Papoz L and the CODIABINSERM-ZENECA PHARMA Study Group. Limitations of the correlation coefficient in the validation of diet assessment methods. Epidemiology 1994; 5: 518-24.

9 Bland JM, Altman DG. Comparing two methods of clinical measurement: a personal history. Int. J. Epidemiol. 1995; 24 S7-13.

10 Beaton GH. Interpretation of results from diet history studies. In: Kohlmeier L, ed. The Diet History Method. Proceedings of the 2nd Berlin Meeting on Nutritional Epidemiology. Nishimura: Smith-Gordon, 1991; 15-38.

11 Kaaks R, Riboli E, Esteve J, van Kappel AL, van Staveren WA. Estimating the accuracy of dietary questionnaire assessments: validation in terms of structural equation models. Stat. Med. 1994; 13: 127-42.

12 Borrelli R, Cole TJ, DiBiase G, Contaldo F. Some statistical considerations on dietary assessment methods. Eur. J. Clin. Nutr. 1989; 43: 453-63.

13 Bland JM, Altman DG. Statistical methods for assessing agreement between two methods of clinical measurement. Lancet 1986 ; i: $307-11$.

14 Ocké MC, Kaaks RJ. Biochemical markers as additional measurements in dietary validity studies: application of the methods of triads with examples from the European Prospective Investigation into Cancer and Nutrition. Am. J. Clin. Nutr. 1997; 65 (Suppl.); S1240-55.

15 Schofield WN. Predicting basal metabolic rate, new standards and review of previous work. Hum. Nutr. Clin. Nutr. 1985; 39C (Suppl. 1): 5-41.

16 Bingham S, Cummings JH. The use of 4-aminobenzoic acid as a marker to validate the completeness of $24 \mathrm{~h}$ urine collections in man. Clin. Sci. 1983; 64: 629-35.

17 Macintyre UE, Venter CS, Vorster HH. A culture sensitive quantitative food frequency questionnaire used in an African population 2 . Relative validation by 7 -day weighed records and biomarkers. Public Health Nutr. 2000 (In press).

18 Grant KI, Langenhoven ML, Stockton MA, Day RS, Bauermeister P. Foodfinder dietary analysis software. Release 1.10. Parowvallei: Medical Research Council, 1992.

19 Maroni BJ, Steinman TI, Mitch WE. A method for estimating nitrogen intake of patients with chronic renal failure. Kidney Int. 1985; 27: 58-65.

20 Larkin F, Metzner HL, Thompson FE, Flegal KM, Guitr KE. Comparison of estimated nutrient intakes by food frequency 
questionnaire and dietary records in adults. J. Am. Diet. Assoc. 1989; 89: 215-23.

21 Statsoft. Statistica for Windows. Tulsa: Microsoft Corporation, 1995.

22 Kaaks R, Riboli E. Validation and calibration of dietary intake measurements in the EPIC project: methodological considerations. Int. J. Epidemiol. 1997; 26 (Suppl.): S15-25.

23 SAS Institute Inc. SAS/STAT Users' Guide, Version 6, Vol. 1, 4th edn. Cary, NC: SAS Institute Inc., 1989.

24 Dunn G. Design and Analysis of Reliability Studies (a Statistical Evaluation of Measurement Errors). London: Edward Arnold, 1989.

25 O'Donnell MG, Nelson M, Wise PH, Walker DM. A computerized questionnaire for use in diet health education. 1. Development and validation. Br. J. Nutr. 1991; 66: $3-15$.

26 Rothenberg E. Validation of the food frequency questionnaire with the 4-day record method and analysis of 24-hr urinary nitrogen. Eur. J. Clin. Nutr. 1994; 48: 725-35.

27 Black AE, Jebb SA, Bingham SA, Runswick SA, Poppitt SD. The validation of energy and protein intakes by doubly labelled water and 24-hour urinary nitrogen excretion in post-obese subjects. J. Hum. Nutr. Diet. 1995; 8: 51-64.

28 Bingham SA, Cassidy A, Cole TJ, et al. Validation of weighed records and other methods of dietary assessment using the $24 \mathrm{~h}$ urine nitrogen technique and other biological markers. Br. J. Nutr. 1995; 73: 531-50.

29 Porrini M, Gentile MG, Fidanza F. Biochemical validation of a self-administered semi-quantitative food frequency questionnaire. Br. J. Nutr. 1995; 74: 323-33.

30 Shetty PS, Henry CJK, Black AE, Prentice AM. Energy requirements of adults: an update on basal metabolic rates (BMRs) and physical activity levels (PALs). Eur.J. Clin. Nutr. 1996; 50 (Suppl.): S11-23.

31 Hayter JE, Henry CJK. A re-examination of basal metabolic rate predictive equations: the importance of geographic origin of subjects in sample selection. Eur. J. Clin. Nutr 1994; 48: 702-7.

32 De Boer JO, van Es AJH, Voorips LE, Blokstra F, Vogt JE. Energy metabolism and requirements in different ethnic groups. Eur. J. Clin. Nutr. 1988; 42: 983-97.

33 Valencia ME, Moya SY, McNeill G, Haggarty P. Basal metabolic rate and body fatness of adult men in northern Mexico. Eur. J. Clin. Nutr. 1993; 48: 205-11.

34 Cole AH, Taiwo OO, Nwagbara NI, Cole CE. Energy intakes, anthropometry and body composition of Nigerian adolescent girls: a case study of an institutionalized secondary school in Ibadan. Br. J. Nutr. 1997; 77: 497-509. 